Seminar Paper No. 523

CIVIL INSTITUTIONS AND EVOLUTION

by

Kaushik Basu

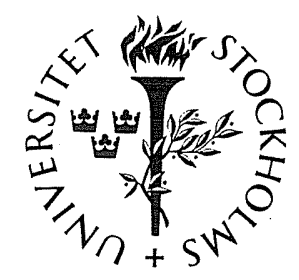

INSTITUTE FOR INTERNATIONAL ECONOMIC STUDIES

Stockholm University 
ISSN 0347-8769

Seminar Paper No. 523

\section{CIVIL INSTITUTIONS AND EVOLUTION}

by

Kaushilk Basu

Seminar Papers are preliminary material circulated to stimulate discussion and critical comment.

September, 1992

Institute for International Economic Studies

S-106 91 Stockholm

Sweden 


\title{
CIVIL INSTITUTIONS AND EVOLUTION
}

\author{
Kaushik Basu \\ Delhi School of Economics \\ Delhi 110007 \\ India
}

This is a revised version of the paper presented at the conference on State, Market and Civil Institutions: New Theories, New Practices and their Implications for Rural Development, held at Cornell University on 13-14 December 1991.

For discussion and comments, I am grateful to V. Bhaskar, Bhaskar Dutta, Marcel Fafchamps, Ajit Mishra, Jeffrey Nugent and the participants at the conference in Abisko, Sweden, 4-7 May 1992, where a variant of this paper was presented. 


\title{
Civil Institutions and Evolution
}

\author{
Kaushik Basu
}

\begin{abstract}
The paper examines the relation between civil norms and evolution. The survival of norms in the long run may depend on the evolutionary process and natural selection. The sieve of natural selection may ensure that norms which persist must have minimal efficiency properties. This paper begins with a general discussion of evolutionary processes and the survival of civil institutions. It then presents an introductory account of the theory of evolutionary games. It is argued that the model of evolutionary games is more suited to analyzing animal behaviour than the human one. Since it is the latter that is of interest to economists, an attempt is made in this paper to develop some new solution concepts which are more apt for human games.
\end{abstract}




\section{CIVIL INSTITUTIONS AND EVOLUTION}

Kaushik Basu

\section{Introduction}

Indians in India do not accept torn currency notes. Englishmen in England do. This need not be because of any inherent difference between Indians and the English. Indians do not accept torn currency notes because other Indians do not accept torn currency notes. Englishmen do because other Englishmen do. In other words, it is possible that both India and England had two potential equilibria - one in which scotch-taped notes are accepted and another in which they are not - and each country is caught in a different equilibrium. Once they are in equilibrium, it is not individually rational to try to deviate from the norm. The norm acquires its own raison d'etre and survives.

When studying the causes of the rise and fall of nations or the technological advance or stagnation of different regions, economists have usually looked for differences in resource availabilities, the appropriateness of government policies and international relations. Thus, in planning to boost agricultural production in a region, we typically wonder whether we should intervene in the credit market to ensure the availability of cheap credit or provide agricultural extension services or stem the adverse movement of the terms of trade between agriculture and industry. What has not however been adequately discussed is the role of different norms. One community may be more prone to taking 
risks than another. Hence, one may be more likely to accept highyielding varieties than the other.

Is such a difference in the attitude to risk between, say, the Punjab farmer and the farmer from Tamil Nadu an inherent difference? The answer may depend on how long a view we take of the matter. In the short-run, of course there are inherent differences. But if we take a sufficiently long view of history, it is entirely possible that these are merely different norms which have evolved from roots which were ance similar.

In textbook economics individuals choose from a set which is constrained by only what their money can buy. In reality, there are additional constraints imposed by the norms of the society or community to which one belongs. These are often very strong and can colour our language and lifestyles. When a Marwari tells you that so-and-so has become a businessman, it is reasonable to assume that he is expressing admiration and perhaps a little envy. When a Bengali tells you the same, it is safe to assume that he is trying his hand at scandal-mongering.

Norms can be economically progressive or regressive. From all accounts, the Protestant work ethic helps economic progress; Rastafarianism does not. Hence, the study of the survival and demise of norms may give us clues to the successes and failures of economies.

Norms however do not appear and vanish overnight. They evolve over long stretches of time and may outlive their original purpose, if any (Basu, Jones and Schlicht, 1987). Their survival in the 
short-run requires that it be individually rational to adhere to these norms. Their survival in the long-run may depend on the evolutionary process and natural selection.

Let me explain this with an example. In Nugent and Sanchez's (1989) paper discussing the Castilian Mesta - the Spanish guild of shepherds with grazing rights so extensive that they often conflicted with the private property rights of landowners - one of the characters, Harry, argues as follows (p. 263) :

"Although the preservation of inefficient institutions is not unheard of (Akerlof, 1976; Basu et al, 1987), in view of the Mesta's very remarkable strength and longevity (having lasted from 1273 to 1836), I suspect that it was serving a socially useful purpose".

But is there any basis to the suspicion of Nugent and Sanchez, alias Harry, that a social purpose was being served? Clearly "longevity" in itself is no explanation. But there may indeed be an indirect link. Longevity of a civil institution guarantees that the institution must have passed the test of natural selection and so must have some minimal usefulness. Hence "Harry's" view can be given an evolutionary justification.

The purpose of this study is to examine the relation between social norms and civil institutions on the one hand and evolutionary processes on the other. The formal analysis of evolution in economics is a relatively recent phenomenon. Its roots are to be found in biology, in particular in the seminal work of Maynard Smith and Price (1973) (see also Maynard Smith, 1982). 
Their analysis of evolutionary games has caught the atcention of economists and there has been an enormous outpouring of writings on it (for references see Van Damme, 1991). This is indeed an important area for economists' interested in development and the growth and decay of norms.

The study of the formation and persistence of social norms, though still in its nascency, has a substantial literature (to name just a few, Akerlof, 1976; Basu, 1986; Platteau and Abraham, 1987; Nabli and Nugent, 1989; Elster, 1989; Sugden, 1989). But none of these papers use results and concepts from the 1iterature on evolutionary games. This paper may be viewed as an attempt to provide a bridge - pontoon, critics would no doubt say - between these two kinds of analyses.

Since evolutionary games have not yet found their way into the development literature, it may be useful to begin with a primer for development economists. This is attempted in section 3 . It is then argued that economists have got excessively involved in the technical solutions of evolutionary games, without paying adequate attention to how these may be adapted to the human context. After al1, Maynard Smith and Price's original paper was called The Logic of Animal Conflict. I suggest ways in which this may be altered to be applicable to human conflict. Finally, I develop a new solution concept which identifies social norms that can survive the sieve of natural selection. 


\section{Institutions and Natural Selection: Preliminary Ideas}

The idea of evolution in society is not one idea but many. And though the infusion of biological game models in the social sciences is very recent, social scientists and philosophers have for a long time talked about the relation between social norms and evolution. One finds evidence of this not only in the works of Schumpeter (1934), Alchian (1950), Hayek (1960), Nelson and Winter (1982) and Jacquemin (1987), but even earlier writers (see Platteau, 1991, for discussion).

To give a somewhat more concrete idea of how evolution can help us understand certain civil institutions, let me begin with an example I have discussed elsewhere (Basu, 1990). It is an example which tries to reject what is often referred to as 'functionalism' and replace it with what may be called 'minimal functionalism'.

It has been noted by anthropologists that in most primitive societies people have 'possessory rights', that is, whoever first gets to possess a good has a right to it. Posner (1981, p. 182) has noted however that in primitive societies where investment is feasible the investor is often protected by the grant of a nonpossessory right. For instance, in a hunter-gatherer society, the trap-setter has the right to a trapped animal instead of the person who first finds the animal. Posner seems to be explaining with this example how societies choose institutions which are optimal for their life-styles. There are others who have adopted more extreme 'functionalist' positions, arguing, for instance, that societies invariably choose laws and civil institutions which are 
functionally optimal or are ones for which benefits outweigh costs. Such naive transplanting of individual choice models on social domains has been rightly criticized by many (see, for instance, Bardhan, 1989) .

It is however possible to argue that though such extreme functionalism is best jettisoned, a 'minimal functionalism' can be defended by a very different route, namely evolution. If one finds that a society which has remained (and therefore survived) unchanged over a long stretch of history has certain norms, it is arguable that these norms cannot be too detrimental for the people. The fact that the people practising this norm have survived such a long time ensures this. Turning to the above example, suppose that there is a hunter-gatherer economy where the trap-setter does not have the right to the trapped animal, but the first person to lay his hands on the animal gets to keep it. In such an economy people would either cease to set traps or, after setting a trap, wait there, foregoing all other activities (such as hunting and gathering). The productivity or 'fitness' of such an economy would be low and it is possible that the economy would not survive too many generations ${ }^{1}$. Hence, hunter-gatherer economies which survive to be analyzed by anthropologists happen to be the ones which grant the trap-setter rights over the possessor. Thus, like the giraffe's long neck and the housefly's resistance to DDT, social groups have norms which serve minimal functions to ensure that they survive ${ }^{2}$ Unlike the colour of my shirt or the location of your house, the norms of a society cannot be explained in terms of human 
volition. Just as lions move in prides not because they choose to do so but because if they did not, their hunting ability would fall drastically and they would not survive to be seen $^{3}$, hunter-gatherer societies may have the norms they do because these norms have survived natural selection or, in Nozick's (1974, p. 314) terminology, 'filter processes'.

To sum up: For us to explain a social norm or civil institution which exists, we must be able to demonstrate (1) that it is individually rational to adhere to the norm once it is there and (2) that it is robust in terms of evolutionary processes. I discussed the method of (1) in Basu (1986) and argued that (1) does not guarantee that the norm is desirable from the society's point of view. Indeed, the norm could be such that every person following it wishes it were never there. On the other hand, to satisfy (2) requires that the norm has at least some minimal desirable properties. Thus, for instance, if we are to explain cooperative behaviour $^{4}$ norms in a society, it seems useful to take the evolutionary approach. Unfortunately, it will be seen that Maynard Smith and Price's 'Evolutionarily Stable Strategy' or phenotype turns out to be necessarily a Nash equilibrium. I shall however demonstrate that my modified solution coricept can admit non-Nash strategies and therefore may be better suited to explaining cooperation.

The above discussion is of an evolutionary process in which there is no explicit recognition of the strategic nature of interaction between agents. This is also true of Nelson and 
Winter's (1982) important work on evolution which differs from the above analysis (especially in its emphasis on the dynamics) and also from the Maynard Smith and Price type of analysis by not drawing out the strategic nature of interactions between agents. This caveat has been noted: see Stiglitz's comment following Nelson's (1986) discursive paper in Stiglitz and Matthewson (1986, p. 473$)$.

The advantage of the recent work on evolutionary games is that interpersonal interdependence is at the centre of the story. It has other shortcomings. But before taking these up, we must do a brief recapitulation of its main ideas.

\section{Evolutionarily Stable Strategies}

When in 1858 Charles Darwin and Alfred Russe11 Wallace presented their path-breaking ideas on the evolutionary origins of human beings to the Linnaean Society in London, the ideas had seemed firmly rooted within the natural sciences. This need not have been so, since Darwin had been influenced by Robert Malthus. Nevertheless, the social sciences had for a long time remained untouched by the rise of evolutionary models in the natural sciences. This is now changing as a consequence of Maynard Smith and Price's (1973) work. Their work on combining evolution with game theory had precursors - the most notable being Lewontin (1961). But in Lewontin's model a species plays games against nature. The distinguishing feature of the work on evolutionary games is that it allows for strategic interaction between players. 
Let $G=\left(S_{1}, S_{2}, P_{1}, P_{2}\right)$ be a two-player normal-form game where $S_{1}$ is player i's set of strategies and $P$ the payoff function. $G$ is an evolutionary game if the following is true:

(i) $S_{1}$ and $S_{2}$ have the same, finite number of elements. We shall write $\mathrm{S}_{\mathrm{i}} \equiv\{1, \ldots, \mathrm{m}\} \equiv \mathrm{S}$.

(ii) The payoff matrix is symmetric. That is, for all $i, j s$, $P_{1}(i, j)=P_{2}(j, i)$. Define $A(i, j)=P_{1}(i, j)$. Note that the entire payoff matrix can be deduced from the function $A$.

From now on we shall hold the $S_{i}^{\prime} s$ as fixed. Hence an evolutionary game is fully defined by $A$. If we write $a_{i j}$ for $A(i, j)$, then the information in $A$ is also fully captured by the matrix $\left[a_{i j}\right]$. Distorting notation a little, I shall write $\left[a_{i j}\right]=A$. Hence $A$ represents both a matrix and a function. It will be clear from the context as to which sense it is being used in.

Let $M(S)$ be the set of all mixed strategies open to player $i$. That is,

$$
M(S)=\left\{x \in E^{\mathbb{D}} \mid \sum x_{i}=1 ; x_{i} \succeq 0, i=1, \ldots m\right\}
$$

where $E^{\mathbb{I}}$ is the m-dimensional Euclidean space. If $x \in \mathbb{M}(S)$ it means that the player will play strategy $i \in S$ with probability $x_{i}$. More generally, if $\mathrm{T} \subset \mathrm{S}$, we define the set of all mixed strategies with support in $\mathrm{T}$ as $\mathrm{M}(\mathrm{T})$.

If 1 and 2 play strategies $x$ and $y$ in $M(S)$, then player $I^{\prime} s$ (expected) payoff is $x^{\mathbb{T}} \mathrm{Ay}$ which, again distorting notation a little, I shall also write as $\mathrm{A}(\mathrm{x} \mathrm{y})$.

Though an evolutionary game looks like any ordinary game with some symmetry conditions added on, its interpretation is very 
distinct. What are called 'strategies' here are not really the 'strategies' of von Neumann and Morgenstern but phenotypes. Each player is a certain phenotype. That is, we could think of each player as born to play a fixed strategy $p \in \mathbb{M}(S)$. Moreover, a $p-$ player's child is also a p-player.

Next, the payoff in an evolutionary game depicts not the level of happiness of agents, but their fitness. Indeed, Maynard Smith (1982) refers to A as the fitness matrix. I shall however take it as will be clear later - that utility coincides with fitness.

Though an evolutionary game is a 2-player game we should think of there being an infinite population. From this, players are randomly matched in pairs and made to play the game A. It is assumed that if in a certain population a strategy $q$ (that is, a player who always plays q) gets a lower expected payoff than strategy $p$, then $q$ will gradually die out from the population because players of type $q$ will have a lower reproduction rate than those of type $\mathrm{p}$.

Now consider a monomorphic population of type $p \in \mathbb{M}(S)$. That is, the entire population consists of agents who play p. Following the discussion in the above paragraph, we shall say that $p$ is immune to $q \in \mathbb{M}(S)$ if

$$
\begin{aligned}
& \text { (1) } A(p, p) \succeq A(q, p) \text { and } \\
& \text { (2) if } A(p, p)=A(q, p) \text {, then } A(p, q) \succ A(q, q) \text {. }
\end{aligned}
$$

Since immunity is such an important element in the definition of ESS, its motivation needs to be spelt out. The usual justification is in terms of 'small invasions' of mutants. I think 
this justification is best formalized in lexicographic terms. Since the bulk of the population consists of type $p$ and a tiny invasion is of type $q$, if $p$ does better against $p$ than $q$ does against $p$, it is reasonable to suppose that $q$ will be less fit than $p$ and get destroyed. Performance against $q$ is of secondary importance. If both $\mathrm{p}$ and $\mathrm{q}$ perform equally well against $\mathrm{p}$, then $\mathrm{q}$ will be less fit than $p$ if $p$ does better against $q$ than $q$ does against $q$. (1) and (2) capture just this idea.

A strategy $p \in \mathbb{M}(S)$ is an evolutionarily stable strategy (ESS) if $\mathrm{p}$ is immune to a11 $\mathrm{q} \in \mathrm{M}(\mathrm{S})-\{\mathrm{p}\}$.

It is clear from (1) that an ESS has to be a Nash equilibrium and over and above that it must have the refinement that comes with (2). Indeed, subsequent analysis shows that it is a very sharp refinement. As ESS is, in fact, not just a Nash equilibrium but also perfect and proper (Van Damme, 1987: theorems 9.3.1 and $9.3 .4)^{5}$. And it is also true that there are games which do not possess any ESS.

Before proceeding with further discussion, note that in the above definition we allow for phenotypes to be mixed strategies. If we want to define an ESS under the presumption that players cannot play mixed strategies, it is easy to modify the above definition. In defining immunity and $E S S$ we have to simply replace $M(S)$, wherever it occurs, with $\mathrm{S}$. In what follows, it will be generally assumed that mixed strategies are allowed. Whenever an assumption to the contrary is used, I shall state it explicitly.

To illustrate this equilibrium concept at work, let us quickly 
review a special case of the well-known Hawk-Dove game (see Maynard Smith, 1982, chapter 2, or Van Damme, 1987, chapter 9).

A player can be aggressive (A) or timid (T). Player $1^{\text {'s }}$ payoffs are given by the matrix below.

Game $G_{1}$

Player 2

$\begin{array}{crrr} & & \mathrm{A} & \mathrm{T} \\ \text { Player } & \mathrm{A} & -1 & 2 \\ 1 & \mathrm{~T} & 0 & 1\end{array}$

This game (2's payoffs are symmetric) has only one ESS: A strategy which plays $A$ with probability $1 / 2$ and $T$ with probability $1 / 2$. In other words, only a population of agents who are aggressive half the time is immune from the invasion of mutants.

Next, consider the game $G_{2}$ described below.

Game $\mathrm{G}_{2}$

Player 2

$\begin{array}{cccc} & & x & y \\ \text { Player } & x & 1 & 0 \\ 1 & y & 1 & 0\end{array}$

Consider a strategy $(p, 1-p)$, which I shall refer to, in brief, as simply $p$. In this $p$ is the probability of playing $x$. Is $p$ an ESS? Note that $A(p, p)=p, A(q, p)=p$, for all $q$. Hence, condition (1) for immunity is satisfied by $p$. Next, note that $A(p, q)=q$. So since $A(p, q)=A(q, q)$, (2) cannot be satisfied. In other words, game $G$ does not possess an ESS. This is somewhat unfortunate, because there is clearly something robust about strategy $x$. Fortunately, as we shall see later, with a very reasonable modification of ESS, $\mathrm{x}$ will be found to be evolutionarily robust. 
This will be so not just in the sense of 'neutral stability', which $x$ satisfies, but in terms of a new solution concept--especially suited to analyzing human conflict--defined below.

\section{The Logic of Human Conflict}

The title of this section is not very original. It simply replaces the word 'animal' with 'human' in Maynard Smith and Price's (1973) classic paper. The intention is to stress the modifications necessary in their model - described in the previous section - in order for it to be applicable to human and social contexts. I shall here focus on two features.

Note that in the above model a player exercises no choice. So players cannot be rational or irrational; their behaviour is inherited and unchanging. Standard game theory on the other hand gives players full freedom to choose from the set of strategies. In reality, human beings are somewhere in between. They choose and optimize over some strategies but also consider some strategies as out of bounds. These latter are determined by a person's inherited training of the norms of the society he lives in. Thus we may choose between several possible careers but may consider picking pockets as something we would not do, whatever the payoffs. There may be others who consider pickpocketing as a reasonable career I have first hand evidence of the existence of such persons. Similarly, in some communities, children are taught to always pay their taxes when they grow up; whereas in others children are taught that taxes ought to be paid if the expected penalty of not 
paying exceeds the amount of tax not paid. What we want to study is which of these norms will survive natural selection.

Let $S$ be the set of all conceivable strategies open to a player. Taking a hint from the above discussion, I shall define a civil norm as any subset, $T$, of $S$. If an agent adheres to civil norm $T$ it means that he chooses the optimal strategy from within $T$ and considers strategies in S-T as ones which one ought not to use. Norms, we shall assume, are inherited.

Under this reformulation, a civil norm is considered evolutionarily robust if it is immune to invasions of small numbers of agents with other civil norms. Note that an ESS would be a special case of this if the civil norms were restricted to unit sets (that is, sets with only one member).

A similar idea is expressed by Nelson (1986, p. 452) when he writes that it is a 'common situation' where 'firms have not thought through the full range of possible actions they might take for any particular set of circumstances', though the underlying reason here has nothing to do with civil norms but arises from the firm's ignorance. But the net effect is the same: the firm chooses from a subset of $\mathrm{S}$.

To appreciate the second problem of ESS, suppose that there is a planet (earth) and people live in different nations. A mutant in one nation is like a migrant. With the notion of a planet and nations interpreted in abstract terms, one can see the importance of the mutant everywhere. A small trickle of migrants from one area to another have at times flourished in the region of their adoption 
and at other times they have perished. The Marwaris in Bengal, the Gujaratis in Maharashtra, the English in India in the eighteenth and nineteenth centuries, the Indians in England today are the success stories. The stories where migrants have done poorly and have become negligible are many more.

It is arguable that in these examples who succeeds and who fails is not so much a matter of inherent traits of a community as a question of chemistry. $\mathrm{X}$ may do well in a population of Ys. The reason why this is at least prima facie possible is because every society has its civil norms. A Scandinavian does not cross a street outside the zebra crossing not because of a rational calculus based on the advantages of doing so minus the expected cost of being caught and fined but because it is not done ${ }^{6}$. A Spaniard in this regard fits much more our description of a homo economicus. To many an Indian, not paying income taxes has the same status as mountaineering. It has its risks but the joys of success frequently outweigh the risks. There is no special moral value attached to this, one way or the other. But for Indians, looking after the old is something you just do; it is not a part of your maximization calculus.

I shall call these gaps in utility maximization a society's normative loopholes. These are things which a person would not do (or would do) purely because they are a norm in his society and irrespective of their utility or payoff consequences. Not breaking queues is a normative loophole of, for instance, Finnish society. I call it a 'loophole' because a mutant or a migrant from another 
society who does not have this norm can presumably exploit this and do well for himself. I believe that the English took such easy control of India in the eighteenth and nineteenth centuries because they exploited the normative loopholes of that India. The Spanish against the early American civilizations was a similar story. The natives were surprised by the range of actions which the invaders were willing to use. The success story behind the Jewish diaspora and also some of the Asian migrants in contemporary times is I think the same one.

In outlining what I called the 'second problem' of ESS as applied to human situations, I have gone on for somewhat longer than originally intended. Some of the ideas motivated will be taken up later. But in the immediate context I want to take up one element of it. If a mutant in one society or nation is a member of another society, a mutant cannot have just any norms but must have a norm which is itself 'stable'. In other words, in defining a stable norm, to ensure that the norm is uninvadable by all conceivable norms is to err on the side of caution. We should instead simply check that it is uninvadable by other stable norms. But note that this introduces recursion in the definition of a stable norm. So we have to proceed with caution towards a setvalued solution concept as, for instance, in Kohlberg and Mertens (1986) and Basu and Weibull (1991).

Though in the end I shall suggest a solution concept which takes account of both these criticisms, it is pedagogically more transparent if it is done in two stages. Thus, in section 5, I 
simply formalize the recursion idea. Then, in section 6, I introduce the idea of a civil norm instead of a strategy as a phenotype; and go on to incorporate both these ideas simultaneously in the solution concept.

\section{Mutants as Migrants}

We shall say that $T \subset M(S)$ is a conclave of evolutionarily stable strategies (CESS) if,

(I) for all $\mathrm{p}, \mathrm{q} \in \mathrm{T}$, such that $\mathrm{p} \neq \mathrm{q}, \mathrm{p}$ is immune to $\mathrm{q}$ and

(II) for all $\mathrm{p} \in \mathbb{M}(\mathrm{S})-\mathrm{T}$, there exists $\mathrm{q} \in \mathbb{M}(\mathrm{S})$ such that $\mathrm{p}$ is not immune to $q$.

The idea of such recursive definitions which result in setvalued solution concepts is not a new one. It has, as already pointed out, been used in game theory in general, CESS being a definition in the spirit of von Neumann and Morgenstern's (1944) "stable set". And even in evolutionary contexts Swinkels (1990) has explored concepts which are related to CESS.

The technical properties of CESS need to be investigated; but that is not my intent here. Instead, let us check how CESS performs in practice. Consider game, $G_{2}$, described above. Though that game, as shown earlier, has no ESS, it has a CESS. Indeed, the reasonable looking outcome $\{x\}$ happens to be CESS. Note that $\{x\}$ satisfies property (I) of CESS trivially. Next, take any mixed strategy q $[0,1]$. It is easy to see that $q$ is not immune against the pure strategy $\mathrm{x}$ (or equivalently against the mixed strategy $\mathrm{p}=1$ ). What is interesting and worth noting here is that CESS allows 
us to explain how non-Nash equilibria could survive in reality. Hence, it gives us a new route for explaining cooperative behaviour in non-cooperative games. I illustrate this with an example.

Game $\mathrm{G}_{3}$

$\begin{array}{lllll} & \text { A } & \text { B } & \text { C } & \text { D } \\ \text { A } & 2 & 1 & 1 & 3 \\ \text { B } & 1 & 2 & 3 & 1 \\ \text { C } & 1 & 3 & 1 & 0 \\ \text { D } & 3 & 1 & 1 & 0\end{array}$

Let us rule out the use of mixed strategies in game G. Notethat $G_{3}$ has no symmetric Nash equilibria. That is, none of $(A, A),(B, B),(C, C)$ and $(D, D)$ is a Nash equilibrium. It will now be demonstrated that $\{\mathrm{A}, \mathrm{B}\}$ is a CESS. Check that $\mathrm{A}$ is immune to $\mathrm{B}$ and $B$ is immune to $A$. Consider next a country of only $C$. This is not immune to B. Similarly, D is not immune to A.

It is not difficult to check that in this game $\{A, B\}$ is the unique CESS. Thus we may have some nations having only type A's and some only B's. Each will withstand the occasional invasion of the other. C and D will not exist. They are the social unicorns and mermaids. We can conceive of them but the earth is too hostile for their survival.

\section{Civil norms}

As discussed in section 4, ideally we should model human beings neither as devoid of rationality, that is, the ability to choose from among strategies (as in the original evolutionary model of section 3 and also in section 4), nor as devoid of civil norms 
which typically constrain the set of strategies from which a person chooses. Thus if $\{x, y, z\}$ are all conceivable strategies open to a person and $z$ entails dipping into other people's pockets, especially in overcrowded buses, in search of $\mathrm{M}_{1}$, then a civil norm could be $\{\mathrm{x}, \mathrm{y}\}$. This norm says that picking pockets is wrong. A person choosing from $\{x, y, z\}$ and endowed with this norm will maximise his utility by selecting a strategy from within $\{x, y\}$.

Consider a game A. As before, the set of pure strategies is given by $S=\{1, \ldots \mathrm{m}\}$. I shall define a restricted game of $\mathrm{A}$ as $(X, Y)$, where $X, Y \subset S$. The payoffs in this restricted game are simply the restriction of the payoff functions $P_{1}$ and $P_{2}$. Thus if the two players choose $(x, y) \quad X x Y$, then $1^{\prime} s$ payoff is $P_{1}(x, y)=$ $\mathrm{A}(\mathrm{x}, \mathrm{y})$ and $2^{\prime}$ 's payoff is $\mathrm{P}_{2}(\mathrm{x}, \mathrm{y})=\mathrm{A}(\mathrm{y}, \mathrm{x})$. Payoffs from mixed strategies are defined as before.

Suppose a person with civil norm $X \subset S$ meets another person with civil norm $\mathrm{Y} \subset \mathrm{S}$, what is the expected outcome? I shall here stay out of the problem of informational asymmetries by assuming that the civil norms of the two players are common knowledge among the two players. If the two players are rational, it may be reasonable to suppose that a Nash equilibrium of the restricted game $(\mathrm{X}, \mathrm{Y})$ will occur. But if $(\mathrm{X}, \mathrm{Y})$ has more than one Nash equilibrium, which one should we expect? I shall get around this by assuming that this is given in the description of the human evolutionary game defined below.

The Nash equilibrium of a restricted game $(X, Y)$ is $p \in M(X)$ and $q \in \mathbb{M}(Y)$ such that $A(p, q) \geq A\left(p^{\prime}, q\right)$, for all $p^{\prime} \in \mathbb{M}(X)$ and 
$A(q, p) \succeq A\left(q^{\prime}, p\right)$, for all $q^{\prime} \in M(Y)$.

Let us define $2^{\mathrm{X}}$ as the collection of all non-empty subsets of $\mathrm{X}$ and recall that $\mathrm{E}$ is the set of real numbers.

A human evolutionary game, $(A, N)$, is an ordered pair such that $A$ is an evolutionary game and $N$ is a mapping, $N: 2^{S} \times 2^{S} \rightarrow E$, such that, for all $(\mathrm{A}, \mathrm{B}) \in 2^{\mathrm{S}} \times 2^{\mathrm{S}}$, there exists one Nash equilibrium in the restricted game (A,B) which gives players 1 and 2 payoffs of $N(A, B)$ and $N(B, A)$.

That every restricted game will have at least on Nash equilibrium is well-known. That a restricted game, $(A, B)$, with $A$ =B, will have a Nash equilibrium with equal payoffs to both players follows from Lemma 9.2.1. in Van Damme (1987, p. 212). Hence, for every evolutionary game, A, we can define at least one human evolutionary game, $(A, N)$.

Given a game $(A, N)$, we define a civil norm as any subset $T$ of $\mathrm{S}^{7}$. We are interested in identifying civil norms which can withstand the arrival of mutants or migrants with other civil norms ${ }^{8}$. This can be easily defined following Maynard Smith and Price's method.

Let $(A, N)$ be a human evolutionary game. The civil norm $T$ is immune to civil norm $X$ if

$$
\begin{aligned}
& \text { (3) } N(T, T) \succeq N(X, T) \text { and } \\
& \text { (4) }[N(T, T)=N(X, T)] \rightarrow[N(T, X) \succeq N(X, X)] \text {. }
\end{aligned}
$$

I shall describe a civil norm $\mathrm{T}$ as an invasion resistant set (IRS) if $\mathrm{T}$ is immune to all $\mathrm{X} \in 2^{\mathrm{S}}-\mathrm{T}$.

Note that an IRS is also a set-valued solution concept though 
it is so in a different sense from CESS. It is worth observing that by virtue of the use of the weak inequality in (4), the IRS is the set-valued counterpart of Maynard Smith's (1982) neutrally stable strategy (see also, Van Damme, 1987, p. 212). I do this in order to prevent a trivial non-existence problem that can arise. As before, we can impose a recursion property on IRS in the same way as was done for ESS in section 5, to get a meta-set-valued solution, which will be called CIRS.

We shall say that a collection of civil norms, $K=\left\{T_{1}, \ldots T_{n}\right\}$, is a conclave of invasion resistant sets (CIRS) if,

(III) for all $T, X \in K$, and $T \neq X, T$ is immune to $X$, and (IV) for all civil norm $T \notin K$, there exists $X \in K$, such that $\mathrm{T}$ is not immune to $\mathrm{X}$.

To illustrate how these solution concepts work and, in particular, how they work differently from standard solution concepts, consider the we11-known Rock-Scissors-Paper game (see Maynard Smith, 1982; and Van Damme, 1987, for discussion) which is illustrated below as game $G_{4}$.

Game $\mathrm{G}_{4}$

$$
\begin{array}{rrrrr} 
& \mathrm{x} & \mathrm{y} & \mathrm{z} & \\
\mathrm{x} & \epsilon & -1 & 1 & \\
\mathrm{y} & 1 & \epsilon & -1 & 0 \leq \epsilon \unlhd 1 \\
\mathrm{z} & -1 & 1 & \epsilon &
\end{array}
$$

As is well known this game has no ESS and no neutrally stable strategy either. However this game has an IRS. In particular, the civil norm $S=\{x, y, z\}$ is an IRS.

The restricted game SxS has only one symmetric Nash 
equilibrium in which each player earns $\epsilon / 3$. Consider now any single-strategy mutant, without loss of generality, say $x$. The restricted game $(\{x\}, S)$ has a unique Nash equilibrium in which $S$ earns 1 and $\{x\}$ earns -1 . Since $-1<\epsilon / 3$, S is immune to $\{x\}$. Next consider two-strategy mutants. Without loss of generality consider the mutant civil norm $\{\mathrm{x}, \mathrm{y}\}$. The restricted game $(\{\mathrm{x}, \mathrm{y}\}, \mathrm{S})$, it can be checked has a unique Nash equilibrium in which $\{x, y\}$ earns $\left(\epsilon^{-1}\right) /(3+\epsilon)$. Since $\left(\epsilon^{-1}\right) /(3+\epsilon)<\epsilon / 3, S$ is immune to $\{x, y\}$. Hence $\mathrm{S}$ is immune to all invasions of civil norms $\mathrm{T} \in 2^{S}-\mathrm{S}$. Hence $\mathrm{S}$ is an IRS.

Next check that, for all $T \in 2^{S}-S, T$ is not immune to $S$. Thus $\{\mathrm{S}\}$ is CIRS.

\section{Progressive and Regressive Institutions}

What section 6 did was to pick up the threads of the various arguments presented in this paper and suggest a framework which seems to be most apt for the analysis of civil norms and institutions. In particular, a method is developed for distinguishing between progressive and regressive civil norms, that is, between, respectively, norms which aid the progress of its adherents and ones which bring about their demise.

In the literature on development much has been written on the role of economic factors in ushering in technical progress. We have learnt of the role of credit availability, extension services, the terms of trade between sectors. What has however been seldom studied - though we do pay frequent lip service to it - is the role 
of social norms and civil institutions. In some societies, hard work is a cause of embarrassment, in others it is a source of pride. In some societies, honesty in speech is an ingrained habit, in others honesty is followed only when this is to one's advantage. Many of these norms get transmitted from parents to children (and from them to their children). To appreciate this, it is useful to distinguish between 'teachings' and 'common teachings'. A teaching $\mathrm{g}$ is what we teach our children; whereas something is common teaching if we teach it to our children, teach them to teach it to their children and to teach their children to teach it to their children, and so on. In a Hindu household, when a parent teaches his or her child karma, it is typically meant to be a common teaching. When a parent teaches his or her child not to use a balcony (for instance, because the railings are broken), this is a teaching without being a common teaching. A common teaching is social science's counterpart of the gene in biology. Civil norms get transmitted from generation to generation through common teachings. The purpose of this study was to develop a model for studying the strengths and weaknesses of civil norms. The model provides a bridge between the optimality claims of some schools of thought and its total negligence in others.

There are several directions that can be fruitfully pursued from here. My general discussion of evolutionary processes in sections 1 and 2 often hint at the importance of 'group selection'.--If a group of identifiable people (for instance, those belonging to the same caste group) are committed to the same norm 
(for example: "never tell lies") it may help the survival of the group vis-a-vis other groups with other norms. In the formal section of the paper the idea of group selection was not pursued. This may however be a line of research which will yield rich dividends in the future.

It may appear at first sight that in this paper I take too stationary a view of norms. After all, norms do change and undergo mutations. While it is true that I did not go into the dynamics of civil norms and institutions, an evolutionary model in no way denies this; and, in fact, may be particularly well-suited to examining such mutations.

An exogenous change that changes the underlying game could well trigger off the demise of existing norms and usher in new ones, just like in England, as industrialization increased, darker moths became better protected from their prey because they blended into the soot laden background and soon these darker moths became the dominant variety. Hence, though the present model is static, my 'human evolutionary games' can be adapted to study the dynamics of civil institutions. 


\section{References}

Alchian, A. (1950), 'Uncertainty, Evolution and Economic Theory', Journal of Political Economy, vol. 58, 211-21.

Akerlof, G. (1976), 'The Economics of Caste and of the Rat Race and other Woeful Tales', Quarterly Journal of Economics, vol. $87,355-79$.

Banerji, A.V. and Weibul1, J. (1991), 'Evolutionary Selection and Rational Behavior', mimeo: Stockholm.

Bardhan, P. (1989), 'Alternative Approaches to the Theory of Institutions in Economic Development, in Bardhan, P. (ed), The Economic Theory of Agrarian Institutions, Oxford, Clarendon.

Basu, K. (1986), 'One Kind of Power', Oxford Economic Papers, vol. 38 .

Basu, K. (1990), Agrarian Structure and Economic Development, Chur, Harwood.

Basu, K., Jones, E. and Schlicht, E. (1987), 'The Growth and Decay of Custom: The Role of the New Institutional Economics in Economic History', Explorations in Economic History, vol. 24.

Basu, K. and Weibull, J. (1991), 'Strategy Subsets Closed Under Rational Behavior', Economics Letters, vol. 36, 141-6.

E1ster, J. (1989), 'Social Norms and Economic Theory', Journal of Economic Perspectives, vol. 3, 99-117.

Fudenberg, D. and Maskin, E. (1990), 'Evolution and Cooperation in Noisy Repeated Games', American Economic Review (Papers and Proceedings), vol. 80, 274-79.

Hayek, F.A. (1960), The Constitution of Liberty, London, 
Routledge.

Jacquemin, A. (1987), The New Industrial Organization, Cambridge, Ma., M.I.T. Press.

Kohlberg, E. and Mertens, J.F. (1986), 'On the Strategic Stability of Equilibria', Econometrica, vol. 54, 1003-37.

Lewontin, R.C. (1961), 'Evolution and the Theory of Games', Journal of Theoretical Biology, vol. 1, 382-403.

Maynard Smith, J. (1982), Evolution and the Theory of Games, Cambridge, U.K., Cambridge University Press.

Maynard Smith, J. and Price, G.R. (1973), 'The Logic of AnimaI Conflict', Nature, No. 246, 15-18.

Nelson, R. R. (1986), 'Evolutionary Modelling of Economic Change', in Stiglitz and Mathewson (1986).

Nelson, R. R. and Winter, S.G. (1982), An Evolutionary Theory of Economic Change, Cambridge, Ma., Belknop Press.

Nozick, R. (1974), Anarchy, State and Utopia, Oxford, Blackwell.

Nabli, M.K. and Nugent, J.B. (1989), 'The New Institutional Economics and its Applicability to Development', World Development, vol. $17,1333-48$.

Nugent, J.B. and Sanchez, N. (1989), 'The Efficiency of the Mesta: A Parable', Explorations in Economic History, vo1. 26, 26184.

Platteau, J.P. (1991), The Free Market is not Readily Transferable: Reflections on the Links between Market, Social Relations and Moral Norms', mimeo: Namur. 
Platteau, J.P. and Abraham, A. (1987). 'An Inquiry into Quasi-credit Contracts', Journal of Development Studies, vol. 23, 461-90.

Posner, R.A. (1981), The Economics of Justice, Cambridge, MA., Harvard University Press.

Schumpeter, J.A. (1934), The Theory of Economic Development, Cambridge, Ma., Harvard University Press.

Stiglitz, J.E. and Mathewson, G.F. (eds) (1986), New Developments in the Analysis of Market Structure, Cambridge, MA., M.I.T. Press.

Sugden, R. (1989), 'Spontaneous Order', Journal of Economic Perspectives, vo1. 3, 85-98.

Swinkels, J. (1990), Three Essays in Game Theory, PhD Dissertation, Princeton University.

Van Damme, E. (1987), Stability and Perfection of Nash Equilibrium, Springer-Verlag.

von Neumann, J and Morgenstern, 0. (1944), Theory of Games and Economic Behavior, Princeton, Princeton University Press.

Wilson, E.O. (1975), Sociobiology, Cambridge, MA., Belknap Press. 


\section{Footnotes}

1. When I talk of a society "not surviving" too many generations, I am not necessarily referring to the case of the society gradually facing Malthusian death. A society can fail to survive because its territories get taken over by pastoralists or colonial invaders. Indeed the idea of survival in the face of invasions is central to the analysis of evolutionary stability as we shall see below.

2. It is a similar idea being expressed by Nelson and Winter (1982, p. 4) when they write: 'Our firms are modeled as simply having, at any given time, certain capabilities and decision rules.... And over time, the economic analogue of natural selection operates as the market determines which firms are profitable and which are unprofitable, and tends to winnow out the latter'.

3. This theory has been attributed to G.B.Schaller by Wilson (1975, p. 504).

4. "Cooperative behavior" usually refers to the choice of strategies which result in Pareto optimal payoffs. Since there is no reason to expect Nash equilibria to be Pareto optimal, explaining cooperation often requires us to use non-Nash solution concepts.

5. Using the framework of repeated games, Fudenberg and Maskin (1990) show that if we introduce mistakes or trembles in the model, an even more drastic refinement becomes possible, in fact one which ensures that only the Pareto optimal among the Nash equilibria can survive.

6. This is, perhaps, not a very good example. During a recent visit to Scandinavia (that is, after I had written the first version of this paper) I got the impression that young Scandinavians at street crossings are beginning to yield to the pressures of individual rationality.

7. An alternative approach would be to require that $T$ be a subset of $M(S)>$

8. Banerji and Weibull (1991) have modelled evolutionary games where phenotypes mingle with rational agents (that is, agents whose civil norms are the entire set of strategies, S). Their model can help us understand the survival chances of rational agents. Phenotypes have the advantage of being able to make commitments, whereas rational agents have the advantage of being able to respond optima11y. 